\title{
ASSESSING THE FUTURE POTENTIAL OF WASTE FLOWS - CASE STUDY SCRAP TIRES
}

\author{
A. PEHLKEN, M. ROLBIECKI, A. DECKER \& K.-D. THOBEN \\ Institute for Integrated Product Development, Bremen University, Germany.
}

\begin{abstract}
Our planet has limited resources, and due to our increasing demands on a variety of products, we rely on the availability of primary and secondary resources. This paper will give an overview on the required information received from processing secondary resources. It is possible to assess the quality of the generated material flows with this information. By describing the material characteristics and the material flow uncertainties, a forecast of the material's future potential to replace primary resources may be possible. Future prospects of the quality of secondary resources, including their input and output properties may be helpful to assess their potential to substitute primary resource for example. It is the contribution of the paper to point out the necessity of knowing the whole life cycle of a product to gain the best available end-of-life option. The case study of scrap tire recycling gives an example of assessing the material's properties. Modeling recycling processes offers the potential of identifying the processing steps with regard to the main material flows and emissions to reduce the environmental impact and improve the economics. Material flow analysis and life cycle assessment can support the determination of the future potential of waste streams entering the recycling process. Some material flows are appropriate to replace primary resources without loss of quality. But other materials are only useful for products with minor quality. Some materials are made to never separate by itself, and therefore pure material flows are impossible to achieve. A model that considers different material properties of material flows helps to evaluate the global recycling potential. Therefore, material qualities have to be defined to make an assessment of sustainable management of secondary resources possible. A concept of developing a model that addresses this issue is presented in this paper. The aim of the model is to predict secondary material flows that are of equal quality of primary material flows. These material flows are then suitable to substitute primary resources which results in global savings in resources, both material and energy.
\end{abstract}

Keywords: Life cycle assessment, material flow analysis, scrap tires, sustainability, uncertainty.

\section{INTRODUCTION}

Primary raw materials are being exploited and countries, especially Europe, depend on imports from other continents. China, for example, produces $95 \%$ of all rare earth concentrates which are commonly used in 'high-tech' products. Motors for hybrid cars cannot be manufactured without rare earth dysprosium. Drilling tools with tungsten tips are vital for the production of compact mobile phones, and rare earth is commonly used in high-performance permanent magnets. Furthermore, China is the top one mining region for other metallic minerals, for example, Antimony ( $87 \%$ of the world production), Tungsten (84\%), Gallium (83\%), and Germanium (79\%) [1]. It is necessary to always have specific raw materials in stock to guarantee a stable production of materials with these ingredients. Also some countries develop 'stockpiling-policies'. If the political situation remains unstable in some countries, it is extremely important to provide raw materials, like Congo, for example, which is the number one world producer of cobalt (36\%). In addition, there are "critical raw materials' defined which are dependent on the supply of the geological resources and reserves of each material. A material is called 'Critical' if over $60 \%$ of its resources are gained from one country [1]. In this case, the stable supply of this material cannot be guaranteed because it relies on the political situation of one country. Another example of a critical material is the fact that some geological resources last only for a few decades. Therefore, the effort to find solutions to either recycle or substitute this material is very high. According to Ziemann et al. [2] the metals, such as Antimony, 
Chrome, Germanium, Gold, and Niobium, can be identified as materials with a high potential to find solutions for substitution.

The resource-efficient and recycling-based industry will strike a balance between dematerialization and rematerialization to support the availability of secondary resources [3]. These secondary resources will enter the common production processes as substitute for primary raw materials. This implies that countries with well-managed recycling process will be less dependent on imports [4].

Secondary resources are not derived from mining or chemical processes compared to primary resources. They are resources that had been already in use and are processed afterwards. Some secondary resources may be waste material in their original application but they might be useful in other applications.

The above-mentioned 'critical metals' can be found in various products as laptops and mobile phones. Table 1 gives an overview on the potential of recovering materials through recycling. In 2008, 1,300 Mio units of mobile phones and 300 Mio units of computer and laptops were sold worldwide. Each mobile phone contains about $250 \mathrm{mg}$ Silver, $24 \mathrm{mg}$ Gold, $9 \mathrm{mg}$ Palladium, $9 \mathrm{~g}$ Copper, and $3.8 \mathrm{~g}$ Cobalt, whereas the numbers in a computer are many times higher [5]. In addition, in 2008, the world consumption of palladium solely for mobile phones and computers were 36 tons. Referring to the world mining production, this amount corresponded to $16 \%$ of the whole production of palladium in 2008. It is evident that the mining industry must be supported through recycling procedures to guarantee sustainable resource consumption for consumers needs. Most raw materials are not endless and therefore we have to save as many resources as possible for future generations.

The goal of each recycling process should be to generate material streams with a quality that ensures further usage in any way. Since it is not possible to achieve this goal for all life cycles, the specific material properties has to maintain as long as possible. Life cycles of secondary resources are often identified as open-loop processes (conversion of material from one product into a new application) compared to closed-loop processes (conversion of material into the same application) (see Fig. 1). While characterizing the output material stream of the first life cycle, the input material stream of the following life cycle is characterized as well. Secondary resources may be used in the same or a new application without being a material with minor qualities. The quality of a secondary material flow is dependent on the recycled product and the recycling process.

Table 1: Impact of world sales of computer/laptops and mobile phones on the mining industry for 2008 [5].

\begin{tabular}{|c|c|c|c|c|c|c|c|c|}
\hline \multicolumn{3}{|c|}{$\begin{array}{l}\text { Mobile phones } \\
\text { (1,300 Mio units / year) }\end{array}$} & \multicolumn{3}{|c|}{$\begin{array}{l}\text { Computer / laptops } \\
\text { (300 Mio units / year) }\end{array}$} & \multicolumn{3}{|c|}{$\begin{array}{l}\text { Percentage at world } \\
\text { mining production }\end{array}$} \\
\hline 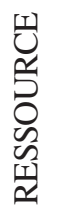 & [mg/unit] & {$[\mathrm{t} / \mathrm{a}]$} & 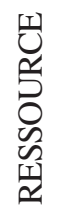 & [mg/unit] & {$[\mathrm{t} / \mathrm{a}]$} & 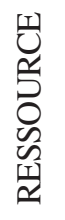 & {$[\mathrm{t} / \mathrm{a}]$} & {$[\%]$} \\
\hline $\mathrm{Ag}$ & 250 & 325 & $\mathrm{Ag}$ & 1,000 & 300 & $\mathrm{Ag}$ & 21,000 & $3 \%$ \\
\hline $\mathrm{Au}$ & 24 & 31 & $\mathrm{Au}$ & 220 & 66 & $\mathrm{Au}$ & 2,400 & $4 \%$ \\
\hline $\mathrm{Pd}$ & 9 & 12 & $\mathrm{Pd}$ & 80 & 24 & $\mathrm{Pd}$ & 220 & $16 \%$ \\
\hline \multirow[t]{2}{*}{$\mathrm{Cu}$} & 9,000 & 12,000 & $\mathrm{Cu}$ & 500,000 & 150,000 & $\mathrm{Cu}$ & $16,000,000$ & $<1 \%$ \\
\hline & \multicolumn{2}{|c|}{ 1,300 Mio Li-Ion Batteries } & \multicolumn{3}{|c|}{140 Mio Li-Ion Batteries } & & & \\
\hline Co & 3,800 & 4,900 & $\mathrm{Co}$ & 65,000 & 9,100 & Co & 60,000 & $23 \%$ \\
\hline
\end{tabular}




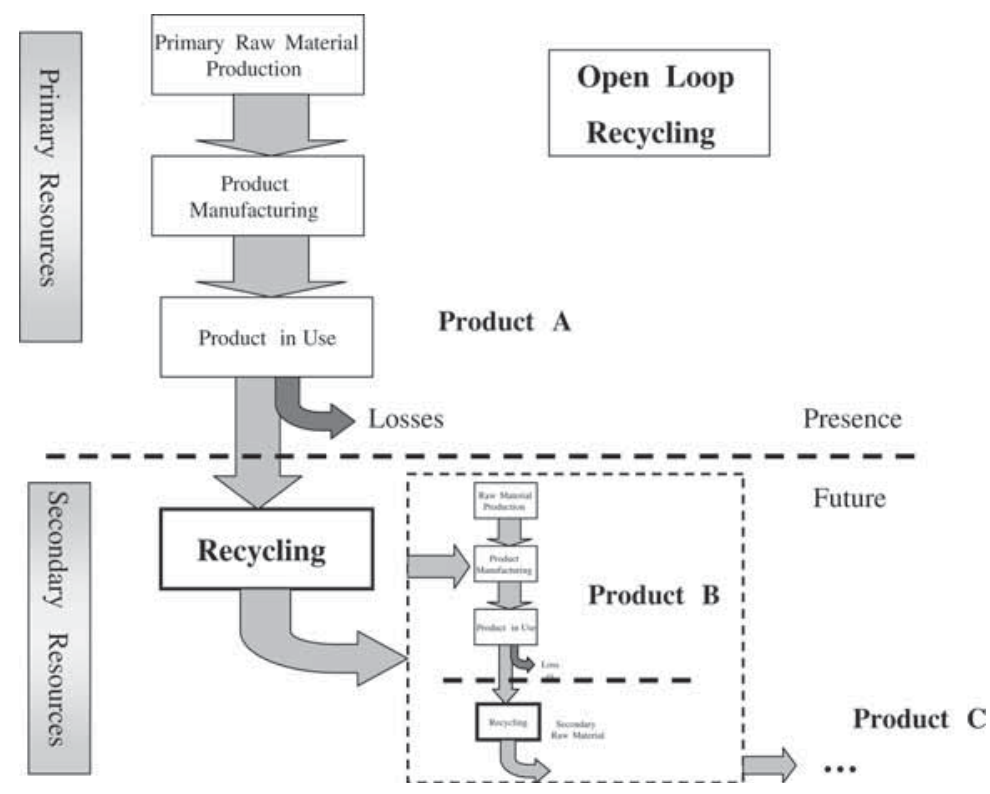

Figure 1: Open-loop recycling process.

The objective of the paper is to add further information to exiting life cycle assessments (LCAs) on waste materials. The case study represents scrap tires. During the life time of a car the tires are replaced many times and therefore the market for scrap tires is growing with growing car market shares. Since tires have different brands and different sizes, the recycling of scrap tires has to cope with different problems as manufacturers of new tires. Highest problem is the guaranteed rubber quality of crushed tires. In this paper, the properties of scrap tires and their output material flows from recycling processes are discussed. The research focus lies on the development of a model that is able to forecast material flows and their quality properties derived from recycling processes. By including material flow properties into LCA-based models, the potential of substituting primary resources through secondary resources should be possible. Primary resources can only be replaced by secondary resources if the quality of secondary resources is of equal quality.

\section{MATERIALS AND METHODS}

\subsection{Software}

LCA, which is used to assess the environmental impacts of products from cradle to grave, is increasingly being applied to the evaluation of waste management strategies. It should be noted, however, that there is a fundamental difference between the life cycle boundaries of products and wastes. The life cycle of a product starts with the extraction of raw materials (through activities such as mining, logging, etc.) and ends with the final disposal of a product. The life cycle of waste starts when a material is discarded into the waste stream and ends when the waste material is either been converted into a resource (such as recycled material or recovered energy) or been finally disposed [6]. 
Since 1992, the Society of Environmental Toxicology and Chemistry (SETAC) is organizing workshops focusing exclusively on uncertainties in LCAs [7]. Modeling recycling processes and the assessment of uncertainty are firmly connected; otherwise, the model provides a lack of reliability due to parameter uncertainties. An interest on the credibility of process modeling due to the performed decisions based on the LCA is evident [8].

Tools to build this recycling process model are the LCA software 'Umberto' Version 5.0 [9] that define the mathematical connections between processing steps as well as the programming language 'Matlab'. It is desirable to forecast specific material properties for choosing processes with the best performance. A rough prediction on material flows, costs, and environmental impacts can be assessed through combining the methods material flow analysis (MFA) and LCA. But these methods lack of the description of material properties and their variations and uncertainties, respectively.

\subsection{Methods}

LCA helps the decision makers in taking into account environmental contribution on the basis of material and energy flows. MFA is a systematic assessment of the flows and stocks of materials within a system defined in space and time [10]. It connects the sources, the pathways, and the final sinks of a material. An MFA delivers a complete and consistent set of information about all stocks and flows of a particular material in a system. The MFA can be regarded as a method to establish the inventory for an LCA.

A short history of MFA and can be found in Binder [11] and is going back to the roots of the 1960s to studies on material balances. The publication of Brunner and Rechberger [10] is now established as a textbook in the application of MFA.

MFA can be easily applied to recycling processes because it takes into account all entering material flows and those which are leaving the recycling process (system boarder). Since the input in recycling processes is often a mixture of various material streams, the exact composition is never known. There is often a lack of information due to unknown parameters in material composition or processing steps [12]. In consequence of the high potential of recycling processes contributing to a sustainable management of resources (e.g. energy savings and material efficiency), it is necessary to assess the material flows with regard to their environmental impact [13, 14]. Assessing the material flows involves the characterization of materials and their properties. According to secondary (recycling) materials this is only possible with determining a range of properties values (e.g. water content lies between 5 and $7 \%$ ).

In general, the following conditions for assessing sustainable resource management in recycling processes have to be achieved:

- Adequate material mass for the recycling process;

- Adequate material mass for further product manufacturing;

- Defined material properties;

- Very little variation of material properties [15].

It is desirable to forecast the above-mentioned conditions for choosing processes that fit best to these conditions and thus achieve a good performance. A rough prediction on material flows, costs, and environmental impacts can be assessed through combining the MFA and LCA methods. While performing an LCA, the evaluation of the environmental impact as carbon footprint, water footprint, ecological footprint, and others is possible [16-18]. As mentioned above, these methods lack the description of material properties, their variations, and uncertainties, 
respectively. Material flows should rather reflect a fundamental basis than being reduced to the assessment of mass and volume. Future prospects of the quality of secondary resources, including their input and output properties, may be helpful in assessing their potential to substitute primary resource, for example.

\subsection{Material: scrap tires}

One scrap tire differs from another scrap tire. There are passenger tires, truck tires, and Off-the-Road (OTR) tires. Some tires are broken, some are just worn, and some are full of dirt which leads to a varying average scrap tire weight. Within these categories, there are different brands with different tire ingredients. Exact tire compositions are not known because each company keeps their compositions secret. As a result, all data are assumptions and an average of all tires. Table 2 shows the composition of a typical European tire [19].

Passenger tires tend to contain more synthetic rubber than natural rubber; truck tires consist of more natural rubber; and OTR tires, including heavy mining tires as well as agricultural and industrial tires, have nearly no synthetic rubber. The rubber composition may be due to the fact that passenger tires have to meet higher quality standards (low rolling resistance, improved skid resistance, and good wear) [20] to succeed in the competitive market. Truck and OTR tires, on the other hand, have to cope with heavy loads and longer distances more than high speed. The fiber content in passenger tires can be as much as 5\% of the total tire weight, whereas OTR tires tend to have little or no fiber content and contain about $15 \%$ steel [21].

The lifespan of an average passenger tire, if properly inflated and well maintained, differs from country to country. For example, the Rubber Association of Canada predicts a lifespan of a wellmaintained steel-belted radial tire of 100,000 km [22]. European tires are estimated to be replaced between 3.5 years or $30,000 \mathrm{~km}$ and 6 years and 80,000 km depending on the mechanical load. An uncertainty in the life time of a tire is the consequence and the exact date when the tire becomes a scrap tire is only estimation. Recipes of tires are changing over the time and therefore only mean values can be used for a simulation. Furthermore, seasonal tires like summer and winter tires vary in their composition as well [12].

Information of material characterization is essential for estimating the material distribution and the material flow. Processing steps like comminution and the following separation depend on each other and are essential for the separation success.

The particle size reduction and the liberation of materials during crushing will both effect the recycling of end-of-life products.

Table 2: Estimated tire composition [19].

\begin{tabular}{lcc}
\hline Composition & Passenger tire weight $\%$ & Truck tire weight $\%$ \\
\hline Natural rubber & 22,0 & 30,0 \\
Synthetic rubber & 23,0 & 15,0 \\
Filling components & 28,0 & 20,0 \\
Rayon & 4,0 & - \\
Polyamid (Nylon) & 1,0 & 1,0 \\
Steel & 13,0 & 25,0 \\
Additives & 9,0 & 9,0 \\
\hline
\end{tabular}


Table 3: Degree of separation and crushing [12].

\begin{tabular}{ll}
\hline Separation degree of materials & Separated \\
& Partly separated \\
& Not separated \\
Crushing degree & Fine \\
& Medium \\
& Coarse \\
\hline
\end{tabular}

Table 3 gives an example on the degrees in separation and crushing. Due to the design and construction of many products, it is difficult to measure exact grain size of the elements in the product. But grain sizes often include the separation of material sizes, and there is a correlation between particle size and separation and/or liberation degree. Most components are well combined and are never made to separate by itself due to quality assurance. In future more attention would be paid to an environmental product design that includes the construction of products to have the potential for easy separation.

According to scrap tires, as case study, there is a strong relation between the liberation of materials and the particle size. Figure 2 shows three different particle sizes of a crushed scrap tire. The coarse particle demonstrates that there is no mechanical processing technology to separate the main materials fiber, steel and rubber from each other. The medium particle indicates that fiber particles are still connected to rubber particles, whereas the fine fraction shows the liberated rubber particle. For further applications, it is necessary to know the 'liberation grade' of particles to evaluate the material properties. Most recycling processes do not separate material flows by $100 \%$. Therefore, the impurities in material flows are essential to know.

Recycling processes generate material flows in various qualities. A complete separation of waste material components is not possible but quality standards can be met through defining separation grades as categories (high, medium, and low). Therefore, modeling is useful to describe the correlation of material properties. It should be noted that the modeling in recycling processes is not related to specific data (numbers) but rather to data ranges (or quality issues). The modeling can help in decision-making processes, if the uncertainty of the model has an acceptable level. The acceptable level depends on the aim of the modeler and the model user.

Scrap tire particles may be classified into groups that provide information on the separation level of particles. After the crushing process, materials may be separated from each other or not [23]. Figures 3 and 4 show the correlation of material separation and particle size.

For the development of new products, most input materials are primary resources. They can be described in their properties since nearly all suppliers of resources participate in a quality management system and provide all their details on material streams. In most cases, material streams generated from recycling processes (secondary resources) cannot compete with primary materials because secondary resources are often a mixture of various components. There is a chance that secondary resources can substitute primary resources, if the information on their properties is complete and are provided through an information system [15]. A parameter of high influence for the process performance is the homogeneity of material streams which is dependent on the sorting and separation success of recycling plants. According to the case study "scrap tires" it can be shown that at the end-of-life of a tire there is no information available on the brand, life time, kind of seasonal tire (winter, summer, or all season), passenger or truck tire, and much more. Besides this information it is never possible to get to know the exact tire composition (because of company secrets) that represents the input of a recycling plant. 


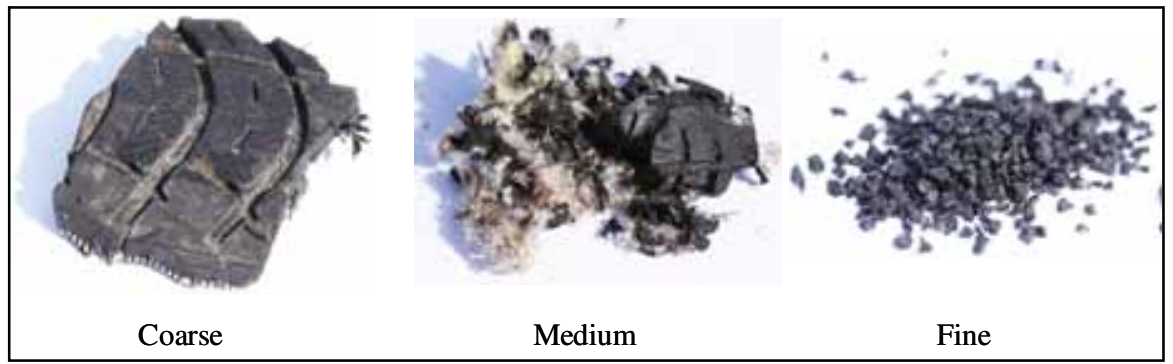

Figure 2: Relation of particle size and liberation grade of scrap tires.

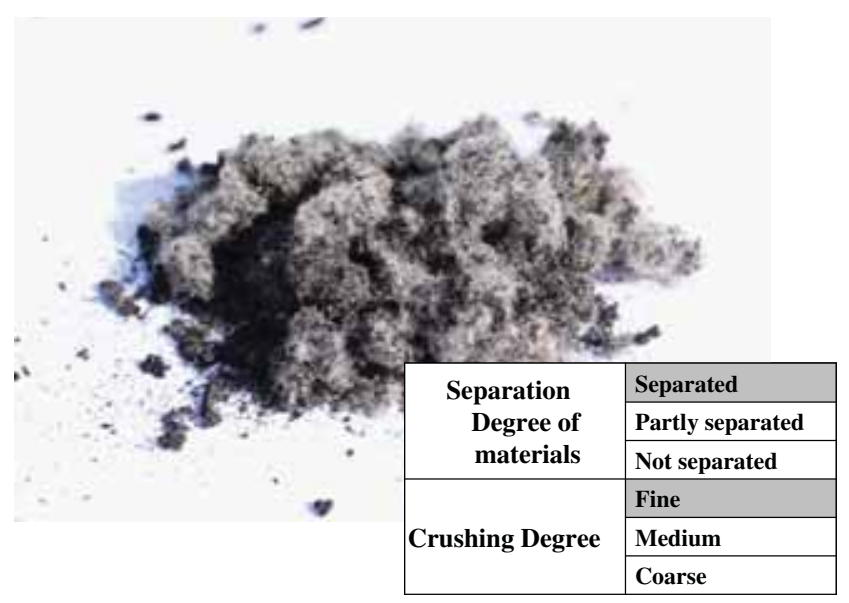

Figure 3: Separated material and small particle sizes of scrap tire particles.

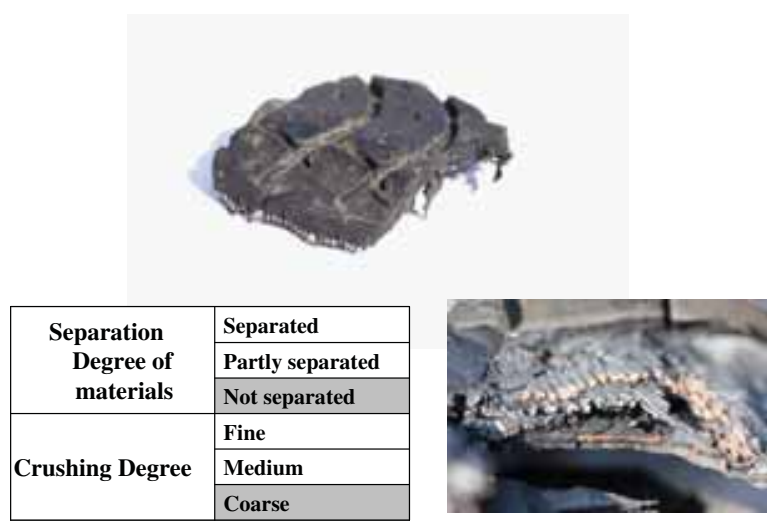

Figure 4: Unseparated material and coarse particle sizes of scrap tire particles. 


\section{RESULTS AND DISCUSSION}

Modeling recycling processes offers the potential of identifying the processing steps with regard to the main material flows and emissions to reduce the environmental impact and improve the economics. Simulation has to be made available for further investigations. The major problems are the uncertainties on the material composition within the material flows, and in the recycled products, especially regarding their characteristics like size, material combination, and distribution. Due to high dynamic uncertainties, a complete LCA cannot be performed for many recycling processes, but life cycle thinking may be applicable. The processes with the main influence must be identified and evaluated within the model.

Modeling solid waste recycling processes is a challenge because there is uncertain specific data available. Various materials are firmly connected to each other that make an ideal separation success nearly impossible. Useful information can be accumulated with data received from particle size distribution. Assessing the information of the separation for modeling purposes with the availability of data ranges and identifying uncertainties is discussed in the following sections.

\subsection{LCA of scrap tires}

The management of product life cycle includes the best knowledge of processes and their system boundaries. All recycling processes that have in common is the fact that their input material has already had a complete life cycle; therefore, it is more difficult to find exact input data for the LCA of the recycling process. Attention has to be paid to uncertainties in performing LCAs in recycling processes. These days life cycles of secondary resources are no longer within the system boundary from 'cradle to grave'; instead, we have to look at a life cycle from 'cradle to cradle' [24].

LCA for scrap tires have been already performed in various publications [25-27]. It is not the intention of this paper to add another LCA to the list. Instead nearly all authors agree to the fact that during the whole life cycle of tires the use phase is the phase with the highest environmental impact and that this impact can only be reduced by proper tire handling (properly inflated) and good quality. The end-of-life phase contributes a far lower environmental impact. Beukering and Janssen state that 'It is not the mass of the tires in use, but the quality of the tires and their management that are decisive in the reduction of environmental pressure caused by the tire life cycle' [27]. Nevertheless all recycling processes should result in the effect that material can be further used to save raw material. A study based on Dutch and German data showed a relation of rubber particle size and the environmental impact of global warming potential. Due to the higher benefit of smaller particles and their possibility to substitute virgin materials, the environmental benefit is higher [28].

\subsection{Process analysis}

Information on recycling processes is not available for all process steps and materials, due to diverse origins of recycling materials. In this case, we applied a metamodel technique. A metamodel describes the structure of a model and mainly uses the information generated from processing steps. This results in an abstract combination of the elements of the model and its linkages. Therefore, this technique allows the development of the model.

A complete separation of waste material components is not possible but quality standards can be met through defining separation grades as categories (high, medium, and low). Therefore, the modeling is not related to specific data (numbers) but rather to data ranges (or quality issues). The modeling can help with the decision-making process if the uncertainty of the model has an acceptable level. The acceptable level depends on the aim of the modeler and the model user. This case 
study represented a trial to study if the modeling is possible at all and therefore the acceptable level was low.

Models to predict the material flows and their properties at the end of the recycling process are essential to close the gap between this information in life cycle management. The developed metamodel describes a theoretical performance of the model on a high level of abstraction to support the construction of a prediction model for real processes. Complex processes are divided into smaller modules with main effects on the process (modular construction system). Since the functional correlation between modules is often unknown, 'black-box' models are in use. These 'black-box' models have direct or indirect influence on the process steps through their input parameters; therefore, they are important for all following process steps.

To obtain the correlation between input and output parameter of the 'black-box' model, laboratory experiments help to identify the relevant process parameter (Fig. 5). These results can then be transferred to an operating plant to confirm the developed module transfer function. Input and output parameters represented the liberation grade of material compounds that could be referred directly to quality properties as described in Figs 2-4. This was used as an indirect measure for material quality assessment. Coarse material particles could be referred to a material compound of various materials, whereas fine material particles refer to a single material. The threshold of being a compound and a single material cannot be determined as a single value but to a value range. The value range is dependent on the material by itself and has to be assessed individually.

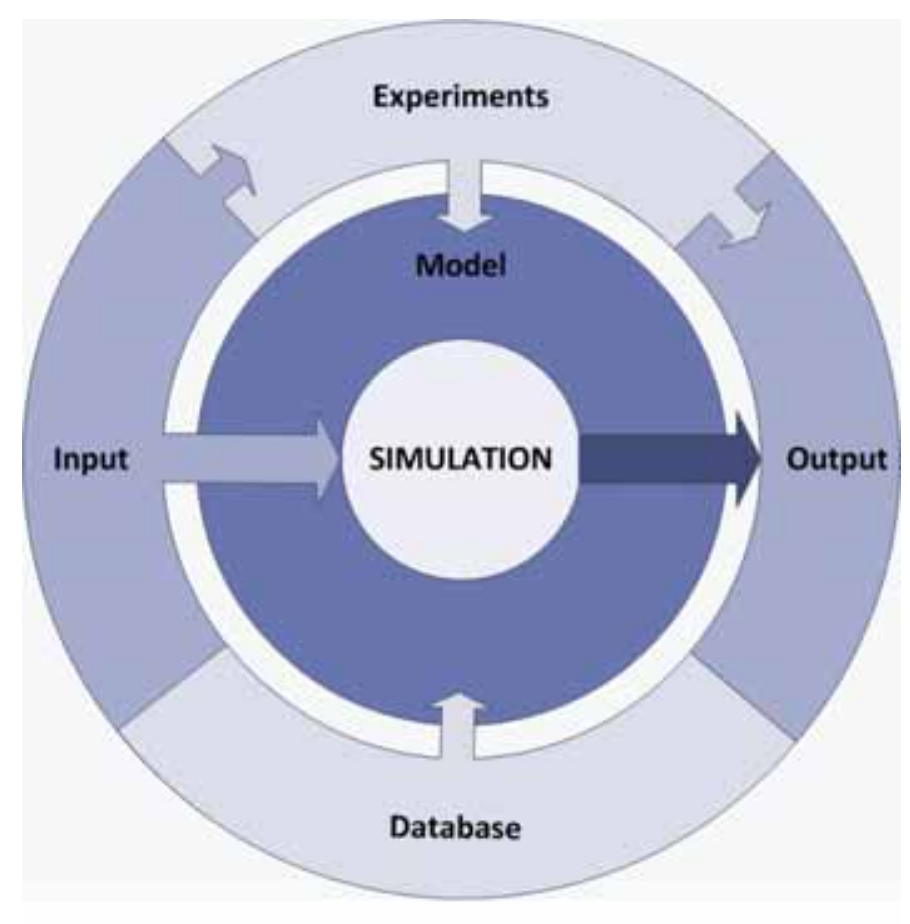

Figure 5: Model development [12]. 


\subsection{Involving uncertainties and transferability}

Uncertainties play an evident role in developing a model to assess a recycling process or support a decision based on environmental impacts of processes. Therefore, uncertainties in the process have to be identified and considered as a fact in recycling processes.

Assessment of the information of the processing steps for modeling purposes with the availability of data ranges and the focus on uncertainties are further determined. Uncertainty can be understood as the variation of a parameter in a model. The variation is not known and is at random. Modeling recycling processes and the assessment of uncertainty are firmly connected; otherwise, the model provides a lack of reliability due to parameter uncertainties. The known and unknown uncertainties of the process become important parameters to consider. Due to the fact that waste materials always vary in their composition and material flows, only data ranges can be used as input parameter [19]. A simulation of recycling processes is therefore often difficult but a model relies on the quality of the process data. For modeling purposes, the acceptable level of uncertainty has to be defined through stochastic methods. In comparison to product development processes, all recycling processes have in common the fact that their input material is not clearly defined and a process model has to cope with a higher impact of uncertainties due to unknown parameter. Compared to the case study of scrap tires, it is never known how many tires of a specific brand with a determined composition are entering the recycling plant. Established methods in product development processes, as described by Pahl and Beitz, [29], are not fully adaptable to recycling processes and have to be further developed.

Possible uncertainty locations are depicted in Fig. 6 and represent only sample locations. Far more locations can be found in processes and have to be taken into account while developing a model.

The known and unknown uncertainties become important parameters to consider in recycling processes. Uncertainties can have many sources and Heijungs and Huijbregts [30] state that the outcome of an LCA is affected by various types of uncertainty, such as parameter, scenario, and model uncertainty. The uncertainty by itself has to be addressed at three places: the input side, the processing side, and the output side. The variation of parameters is not always known and coincidental. For example, there is data for which no value is available, data for which an inappropriate value is available, and data for which more than one value is available. Due to the fact that residues always vary in their composition and material flow, only data ranges can be used as input parameter. Therefore, a simulation of recycling processes is often difficult. Notten and Petrie [31] substantiate the statement that 'different sources of uncertainty require different methods for their assessment'. For

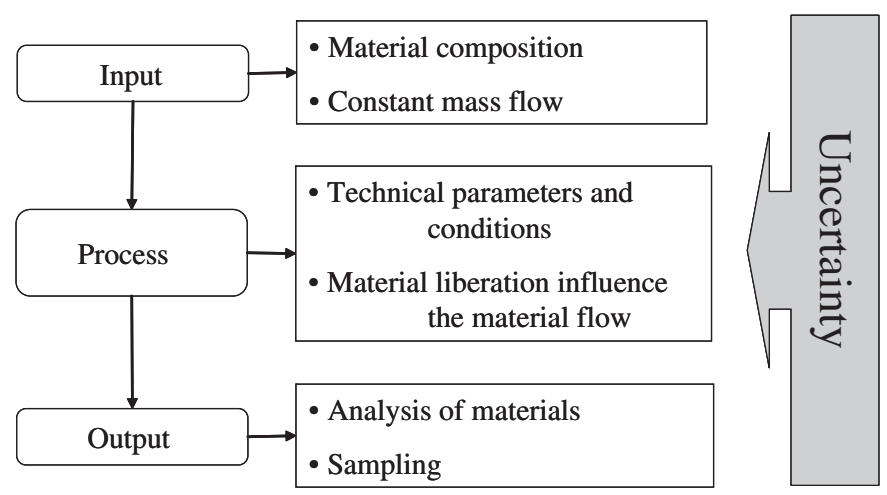

Figure 6: Possible uncertainty locations. 
that reason, the model relies not only on the quality of the process data but also on the uncertainty assessment [32].

The material properties are as important as the variation of quality attributes as impurities, for example. Excellent material properties cannot be managed if they underlie extreme variations and are not reliable and reproducible, respectively. Substance values are reproducible if - when repeating the sampling procedure - the new set of one or more substance values is statistically indistinguishable from the original one (i.e. the statistics of interest [e.g. means] do not differ significantly). The reproducibility must be guaranteed over the whole processing time to obtain a material stream with constant properties and therefore ensures the process capability.

As mentioned above, the particle size plays an important role in recycling processes. Scrap tires, for example, are first crushed and then further processed in other process steps that are mainly dependent on the particle size. In this case, the 'black-box' model depicts the modification of particle distribution with their correlation between the single particle size fractions. Various statistical methods have been tested to fit the best transfer function.

For process modeling, it is necessary to describe the particle distribution. Particle size distributions often follow a normal or Weibull distribution. In this case, parameter like variation or variance of the specific distribution can be easily compared by density functions. Figure 7 compares the mean values of different particle size distributions of crushed scrap tires. Assumptions according to the Shapiro-Wilk test have shown that the distributions follow a normal distribution. The statistical possibility for the true value is expected to be in one confidence interval. The size of the interval is dependent on various parameters like mean variation or data numbers for mean determination. According to this issue, the authors investigated the similarities of the distributions and identified that they were able to differentiate the particle size distribution by its mean value ranges. A higher content of material B related to smaller particle size.

Comparing the confidence interval of the mean values (in Fig. 7 it is demonstrated through a diamond and circle icon) complicates the differentiation. Intervals have to be clearly separated for a

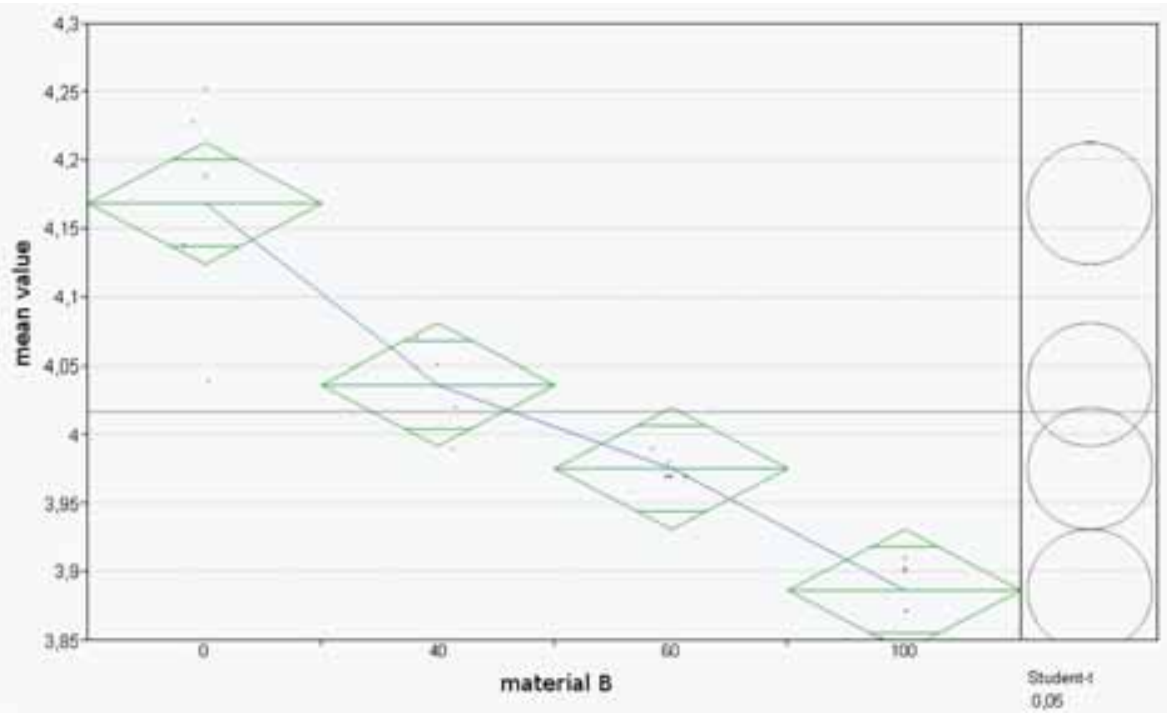

Figure 7: Statistical evaluation of crumb rubber analysis. 
mathematical well-defined conclusion; otherwise, there are multiple solutions that are valid. Figure 7 indicates that all material mixes are separated and the diamonds are not crossing each other. Therefore, only the mixture of $40 \%$ material B and $60 \%$ of material B shows no significant differentiation due to the overlapping diamonds.

Main advantage of the particle size distribution as a density function is the mathematical definition: It is always the sum of $100 \%$. This is essential for simulation purposes due to the relation between input and output streams. Every stream that goes into a system has to leave the system otherwise it causes an error. Therefore, the whole particle size distribution has to alter in all particle classes. Referring to density functions, the mean and variation can vary but the complete function remains.

\section{MODEL APPLICATON TO A TIRE RECYCLING PLANT}

The evaluation of the model was performed at an operating tire recycling plant with a capacity of 30,000 tons scrap tires annually. The input in the plant presented whole scrap passenger and truck tires, whereas the highest interest on the output represented crushed rubber crumbs in various particle sizes. Other material output was identified as steel and fiber. The focus was on the rubber flow, since this is the material flow of highest interest for the tire recycler. Statistical laboratory experiments on rubber particle sizes were carried out to describe the transfer function of the crushed rubber particles. This information is essential for simulation purposes to evaluate the potential of the material flow for further processing.

In general, the particle size of recycling materials is often connected to the liberation grade, as mentioned in section 2.3. This information is needed for further use of material flows in following applications. The demand on material properties of rubber particles for use in automotive parts differ from the one which are used on playgrounds, for example. The model has to cope with information like coarse, medium, and fine particles and quality issues like contamination of rubber with textile particles, steel with rubber particles, and further more. To deliver a reliable result, the model has to cope with the variation of material properties. Processing of information and data has a major influence on the model output.

A model has been developed using the software Umberto [9] and the process steps with main influence on the materials like crushing, magnetic separation, and sieving were included in the flow network. Properties of material flows were described with the help of the statistical experiments on rubber particles.

The output material can be identified as a result of the information of the preceding stages. Main influence on the modeling is the crushing process, since this is the process stage of main influence on the material properties. Through this process, materials are liberated and therefore separable.

Despite the incomplete information on the recycling plant due to company secrets and the missing opportunity to vary parameters in the plant operation, the authors were able to simulate own process data through Monte Carlo Simulation in Umberto. Monte Carlo simulation, or probability simulation, is a technique used to understand the impact of risk and uncertainty in forecasting models. It is necessary to make certain assumptions during the development of a forecasting model. In this case study of scrap tires, the authors had to make assumption of the varying distribution of material flows. By using the assumptions, based on the knowledge of material compounds and the use of separation technology, the authors were able to forecast possible material availability. They chose 1,000 repeats and applied the Weibull distribution to their own findings on rubber crumb characterization. With these findings it might be possible to assess the availability of certain secondary material flows that are received from recycling processes. These materials can substitute primary resources, if they meet certain quality requirements. 
To show comparable results, it is necessary to gather more information on the recycling process and its process steps. The transferability of the model on an operating plant is incomplete due to missing data. However, first attempts have shown that the metamodel's functionality is dependent on the accessibility of process and material information.

The model is based on Petri nets - as available in Umberto. Petri nets are alternative tools for the study of non-deterministic, concurrent, parallel, asynchronous, distributed, or stochastic systems. They can model systems in a natural way. Furthermore, the Petri nets approach can be easily combined with other techniques and theories such as object-oriented programming, fuzzy theory, neural networks, etc. [33]. Since Petri nets offer advantages to model systems and can interact with other techniques easily, this approach is the base for the developed model. The authors suggest a hybrid system which combines Petri nets and neural networks with a case-based reasoning approach, thereby enabling field uncertainties. They used the advantages of Petri nets in order to overcome the neural network deficiencies concerning their original design and definition of their initial weighs. The solution solves uncertainty problems of process data defects using neural networks and casebased systems together. Recovered similar cases have allowed the readjusting the network solutions as well as the correction data. Another advantage would be to propose several solutions to experts.

Neural networks are used in different fields. Classification is one of problems where they are commonly and very often used. The back-propagation algorithm is one of the most widely used method for training feed-forward neural networks because of its simplicity and capability to extract useful information from the examples and implicitly store it in their weighing connections $[34,35]$. This algorithm has some limitations in its practical use that are generally approached and accepted by researchers. Some of these limitations are that the convergence toward a state of minimum error can be extremely slow, mainly if the size of the network is not big enough with regard to the size of the problem. Next, it can standby in local minima before finishing the learning of all the examples, and finally, it is almost impossible to select the design of the network before hand [36]. Due to its complexity and slow process, a lot of software was developed to help the designers of these networks in the design and implementation of multilayer perceptrons (MLP). New training algorithms are implemented to achieve results similar to the traditional ones, in a very short time. Petri nets are alternative tools for the study of non-deterministic, concurrent, parallel, asynchronous, distributed, or stochastic systems. They can model systems in an easy and natural way. Furthermore, the Petri nets approach can be easily combined with other techniques and theories such as object-oriented programming, fuzzy theory, neural networks, etc. These modified Petri nets are widely used in computing, manufacturing, robotic, knowledge-based systems, process control, as well as in other kinds of engineering applications [33]. Since Petri nets offer advantages to model systems and can interact with other techniques easily, it would be advantageous to model neural networks starting from Petri net models, which allow not only the design adjustment but also the initialization of the neural network weights. Following the algorithm proposed by Xiaoou $\mathrm{Li}$ and Wen $\mathrm{Yu}$ [36], a neural network can be modeled starting from a Petri net with the application of weighty production rules in the algorithm. The learning algorithm of the neural networks obtained is the same as the back propagation of multilayer neural networks. The main idea is that all layer weights can be updated through the back-propagation algorithm if certainty factors of all sink places are given [35]. A complex neuronal network can be divided into several sub-networks starting from the modular design of an original Petri net. The designed sub-networks will correspond to the real application of sub-processes.

\section{CONCLUSION}

The focus on the management of secondary resources has increased in the last years. Due to limited primary resources and the effort to live in a sustainable environment, waste management and the 
involved recycling technologies will improve. MFA and LCA support the determination of the future potential of waste streams entering the recycling process. Some material flows are appropriate to replace primary resources without loss of quality (up-cycling). But other materials are only useful for products with minor quality (down-cycling). Some materials are made to never separate by itself and therefore pure material flows are impossible to achieve. A metamodel that considers the fact of material flows of different material properties may help to evaluate the global recycling potential. Therefore, material qualities have to be defined to make an assessment of sustainable management of secondary resources possible.

Information on material properties generated with LCA and MFA can contribute to the product design, the production phase, and the recycling performance of a product. Traditional LCA models are static and are not suitable for dynamic modeling.

To be able to plan for changes in waste flows, decision-makers require future studies of material flows. A high potential on research work is identified according to the field dynamic modeling to forecast material flows with regard to LCA.

Uncertainties are often related to recycling processes and therefore it is necessary to take into account the consequences of their impact on assessment methods. Neglecting uncertainties should be the last option when compared to the establishment of rules and models that are able to cope with uncertainties. Research on uncertainties or data defects, like missing data, is of high interest.

Further research is necessary in the field of waste flow modeling and the handling of uncertainties. Fuzzy methods and neural networks may solve the problem but there are still a lot of open questions.

The modeling of recycling processes would improve if more information on used materials in a product is accessible. All recycling processes have in common the fact that they have to undergo a 'practical training' since the input material is never known exactly. It would be more effective for plant operators if they have more information on the whole products life cycle. In general, additional information on process steps and material properties should be more accessible through databases. This is a requirement for the development for a model that delivers reliable results on secondary resources through recycling processes. Without the connection with database, every single model is just a solution for one single problem.

For a reliable assessment of waste flows it is necessary to rely on fundamental data. Therefore, the accessibility of material data bases and existing recycling networks is highly beneficial for materials flow models. Only by monitoring the highly fluctuating recycling market a model is of value for authorities who may use a model for forecasting material flows for the coming years for strategic planning. This can only be achieved by making the whole life cycle of products more transparent, thus, beginning with the manufacturer.

\section{ACKNOWLEDGMENT}

The authors extend their sincere thanks to the German Research Foundation (DFG) who funded the project Metadis at Bremen University.

\section{REFERENCES}

[1] Commission of the European Communities. The raw material initiative - meeting our critical needs for growth and jobs in Europe, Communication from the Commission to the European Parliament and the council, COM (2008) 699, Brussels, Belgium, 2008.

[2] Ziemann, S., Schippl, J., Grunwald, A. \& Schebek, L., Verfügbarkeit knapper metallischer Rohstoffe und innovative Möglichkeiten zu ihrer Substitution. Rohstoffeffizienz und Rohstoffinnovationen, Fraunhofer Verlag: Stuttgart, Germany, 2010. 
[3] Angerer, G., Erdmann, L., Marscheider-Weidemann, F., Scharp, M., Lüllmann, A., Handke, V. \& Marwede, M., Rohstoffe für Zukunftstechnologien - Einfluss des branchenspezifischen Rohstoffbedarfs in rohstoffintensiven Zukunftstechnologien auf die zukünftige Rohstoffnachfrage. ISISchriftenreihe "Innovationspotenziale"; Fraunhofer IRB: Stuttgart, Germany, 2009.

[4] EPA (9). Sustainable materials management: The road ahead (report and appendix - technical support document, Washington DC: EPA, available at www.epa.gov/epawaste/inforesources/ pubs/vision.htm (accessed February 2010).

[5] Hagelüken, C. \& Meskers, C.E.M., Mining our computers - opportunities and challenges to recover scarce and valuable metals from end-of-life electronic devices. Proceedings of Electronics Goes Green 2008+, eds H. Reichel, N.F. Nissen, J. Müller \& O. Duebzer, Fraunhofer IRB: Stuttgart, Germany, 2008.

[6] EPIC-Environment and Plastics Industry Council and CSR-Corporations Supporting Recycling. Integrated Solid Waste Managements Tools: "Measuring the Environmental Performance of Waste Management Systems". October 2000.

[7] Fava, J.A., Jensen, A.A., Lindfors, L., Pomper, S., de Smet, B., Warren, J. \& Vigon, B., Life Cycle Assessment Data Quality. A Conceptual Framework. Society of Environmental Toxicology and Chemistry \& SETAC Foundation for Environmental Education, Inc.: Washington, DC, 1994.

[8] Pennington, D.W., Potting, J., Finnveden, G., Lindeijer, E., Jolliete, O., Rydberg, T. \& Rebitzer, G., Life cycle assessment part 2: current impact assessment practice. Environment International, 30, pp. 721-739, 2004. doi: http://dx.doi.org/10.1016/j.envint.2003.12.009

[9] IFU Hamburg GmbH, Germany Umberto 5 Software, Version 5.5, 2010.

[10] Brunner, P. \& Rechberger, H., Practical Handbook of Material Flow Analysis. Advanced Methods in Resource and Waste Management. Lewis Publishers: Boca Raton, USA, 2003. doi: http://dx.doi.org/10.1201/9780203507209

[11] Binder, C.R., van der Voet, E. \& Rosselot, K.S., Implementing the results of material flow analysis. Journal of Industrial Ecology, 13(5), pp. 643-649, 2009. doi: http://dx.doi.org/10.1111/ j.1530-9290.2009.00182.X

[12] Pehlken, A. \& Mueller, D.H., Using information of the separation process of recycling scrap tires for process modelling. Resources, Conservation and Recycling, 54, pp. 140-148, 2009; Available at http://dx.doi.org/10.1016/j.resconrec.2009.07.008

[13] Bringezu, S. \& Bleischwitz, R., Sustainable Resource Management: Global Trends, Visions and Policies, Greenleaf Publishing Ltd: Sheffield, UK, 2009.

[14] Salhofer, S., Wassermann, G. \& Binner, E., Strategic environmental assessment as a participatory approach environmental planning: experiences from a case study in waste management. Complexity and Integrated Resources Management. iEMSs 2004 International Congress. In: C. Pahl-Wostl, S. Schmidt, T. Jakeman (Hrsg.), International Environmental Modelling and Software Society: Osnabrueck, Germany, 2004.

[15] Pehlken, A. \& Thoben, K.-D., Contribution of Recycling Processes to Sustainable Resource Management. 18 ${ }^{\text {th }}$ CIRP International Conference $n$ Life Cycle Engineering (LCE 2011), Braunschweig, Germany, 2011.

[16] Ekvall, T., Assefa, G., Björklund, A., Eriksson, O. \& Finnveden, G., What life cycle assessment does and doesn't do in assessments of waste management. Waste Management, 25(3). pp. 263-269, 2007.

[17] Fatta, D. \& Moll, S., Assessment of information related to waste and material flows - a catalogue of methods and tools. technical report 96 of the European Environment Agency: Copenhagen, 2003. 
[18] Hashimoto, S. \& Mariguchi, Y., Proposal of six indicators of material cycles for describing society's metabolism: from the viewpoint of material flow analysis. Resources Conservation and Recycling, 40, pp. 185-200, 2004. doi: http://dx.doi.org/10.1016/S0921-3449(03)00070-3

[19] Wdk, Wirtschaftsverband der deutschen Kautschukindustrie (Organisation of the German manufacturers of tyres and technical elastomers products), personal information, 2003.

[20] Dunn, JR. \& Jones, RH., Automobile and truck tires adapt to increasingly stringent requirements. Elastomerics, 123(7), pp. 11-18, 1991.

[21] www.rma.org (accessed November 2011).

[22] Rubber Association of Canada, available at www.rubberassociation.ca (accessed December 2011).

[23] Pehlken, A., Decker, A., Müller, D.H., Thoben, K.D., Todt, S. \& Rolbiecki, M., Modellierung von Stoffstromeigenschaften im recycling. Müll und Abfall, S, pp. 386-391. 08/2009.

[24] Braungart, M. \& McDonough, W., Cradle to Cradle. Remaking the Way We Make Things, North Point Press: New York, 2002.

[25] Fiksel, J., Bakshi, B.R., Baral, A., Guerra, E. \& DeQuervain, B., Comparative life cycle assessment of beneficial applications for scrap tires. Clean Technologies and Environmental Policy, 13(1), pp. 19-35, 2010. doi: http://dx.doi.org/10.1007/s10098-010-0289-1

[26] Clauzade, C., Osset, PH., Hugrel, CH., Chappert, A., Durande, M. \& Palluau, M., Life cycle assessment of nine recovery methods for end-of-life tyres. International Journal of Life Cycle Assessment, 15, pp. 883-892, 2010. doi: http://dx.doi.org/10.1007/s11367-010-0224-Z

[27] Beukering, P.J.H. \& Janssen, M.A., A dynamic integrated analysis of truck tires in Western Europe. Journal of Industrial Ecology, 4(2), pp. 93-115, 2000. doi: http://dx.doi.org/ $\underline{10.1162 / 108819800569825}$

[28] Genan Business; Comparative Life Cycle Assessment of two options for waste tyre treatment: material recycling vs. Co-incineration in cement kilns, Company report, available at http:// www.genan.eu/life_cycle_assessment-91.aspx, Denmark, 2009.

[29] Pahl, G. \& Beitz, W., Konstruktionslehre - Methoden und Anwendung, Springer: Heidelberg, Germany, 1993. doi: http://dx.doi.org/10.1007/978-3-662-08164-8

[30] Heijungs, R. \& Huijbregts, M.A.J., A review of approaches to treat uncertainty in LCA. iEMS Conference Proceedings: Complexity and Integrated Resources Management. Osnabrueck. Germany, 2004.

[31] Notten, P. \& Petrie, J., An Integrated Approach to Uncertainty Assessment in LCA, International Workshop on LCI-Quality: Karlsruhe. Germany, 2003.

[32] Clyde, M., \& George, E.I., Model uncertainty. Statistical Science, 19(1), pp. 81-94, 2004. doi: http://dx.doi.org/10.1214/088342304000000035

[33] Arco, L., Bonet, I., Marx Gómez, J. \& Rautenstrauch, R., A new approach to solve data defects in material flow networks. Proceedings of 19th International Symposium on Environmental Informatics - Networking Environmental Information - EnviroInfo, ed. J. Hrebizek, Brno, (Czech Republic), pp. 724-731, 2005.

[34] Hilera, J., Redes Neuronales Artificiales: Fundamentos, Modelos y Aplicaciones, Ed. AddisonWesley: Iberoamericana, 1995.

[35] Yu, X., Chen, G. \& Cheng, S., Dynamic learning rate optimization of the backpropagation algorithm. IEEE Transaction on Neural Networks, 6(3), pp. 669-677, 1995. doi: http://dx.doi. org/10.1109/72.377972

[36] Li, X. \&Yu, W., Dynamic knowledge inference and learning under adaptive fuzzy Petri net framework. IEEE Transactions on Systems, Man, and Cybernetics - Part C: Applications and Reviews, 30(4), pp. 442-450, 2000. doi: http://dx.doi.org/10.1109/5326.897071 